Prescribing

\title{
The launch of the British National Formulary for Children
}

\section{A Elias-Jones, G Rylance}

\section{A definitive formulary}

O n 14 July 2005, the official launch of the British National Formulary for Children (BNF-C), attended by $\mathrm{HRH}$ Princess Anne, was hosted at the Royal College of Paediatrics and Child Health ( $\mathrm{RCPCH})$.

This definitive formulary is the result of cooperation between the British National Formulary team (BNF) and the team that produced the Medicines for Children (MfC) books whose second editions were published in September 2003.

There has been a clear recognition that children have been disadvantaged by the requirement to receive medicines not licensed for use in children or off label applications. Studies have shown the problem to be worse still in neonatal practice where up to $93 \%$ of babies receive at least one unlicensed or off label medicine during their stay in intensive care. ${ }^{1}$ The use of unlicensed drugs and off label carries significant risks highlighted in many publications. ${ }^{23}$

Hence, the first edition of Medicines for Children was published by RCPCH Publications Ltd in 1999. The work involved in producing the book was an immense achievement and involved the cooperation of many paediatricians with expertise in paediatric prescribing and members of the Neonatal and Paediatrics Pharmacists Group (NPPG) under the supervision of the RCPCH Medicines Committee chaired by Professor Sir David Hull. The pocket book edition followed in 2001. These books have rapidly become established as the definitive prescribing books for neonates and children in the UK and beyond. Indeed, an Italian version (Guida all'uso dei farmaci per $i$ bambini) edited by Professor Maurizio Bonati was published in 2002. Since then, the Indian Academy of Paediatrics has printed the book locally for use on the Indian subcontinent.

So why shelve Medicines for Children and place trust in the BNF organisation to uphold principles and maintain standards? Many paediatricians and pharmacists spent large amounts of time in research, writing, reading, and editing for MfC. It was clear that goodwill would not continue to provide a secure base for future successful editions, keep pace with new developments, and publish up to date advice; assistance from an external source with a track record and expertise in publishing definitive formularies was required. Most things change with time and the BNF partners indicated that they were keen to collaborate in partnership with the RCPCH and NPPG. The combined strength and resources of the new partnership would be expected to provide an improved database for a new publication, and in-house staff with high professional standards and technical expertise would bear the brunt of information research, presentation, and editing. An editorial committee has worked on the first edition (July 2005) for more than a year. Its membership included representatives of the College, NPPG, BMA, Royal Pharmaceutical Society of Great Britain, Medicines and Healthcare products Regulatory Agency (MHRA), and the Royal College of General Practitioners.

Additional support to the provision of prescribing information was announced by Lord Warner (Health Minister) on 17 August 2004:

"...until now there hasn't been enough emphasis on developing medicines specifically for use in children, and the UK has led the way in pushing for change in this areawork is in progress on a British National Formulary for Children and we provide funding for its publication and distribution as soon as it is ready. I want the new strategy that I have announced today to give a strong message to pharmaceutical companies to focus on the needs of children when developing new medicines."

Lord Warner also announced that part of the funds allocated in the Budget were to be directed to the Medicines for Children Research Network (MCRN), which is part of UK Clinical Research Network. Since then, a consortium from the University of Liverpool, Royal Liverpool Children's Hospital, Imperial College London, The National Perinatal Epidemiology Unit (University of Oxford), Liverpool Women's Hospital, and The National Children's Bureau have established the Coordinating Centre for the MCRN.

BNF-C will be different from MfC. Distributed free to all doctors, pharmacists, and dental practitioners, it will have an enlarged and perhaps different readership—neonatologists and general practitioners were infrequent users of MfC. BNF-C is designed to meet their needs as well. From the BNF stable, it will follow the same format as the standard BNF so that users of both publications will find it easy to use. However, there will be significant differences. A new page format and colour highlighted text for clarity and easy accessibility may lead the way for the BNF to follow. The long wait for a much needed electronic PDA version of the major British paediatric prescribing guide should end in about September/ October of this year. The ease of use of an alphabetical listing of drugs will be practically realised in the PDA version, though not in the book. The Department of Health, in addition to supporting this publication, is encouraging the development of a BNF-C website with increasing sophistication over time to assist timely, accurate, and error free prescribing.

The production process involving inhouse BNF-C staff (four whole-time equivalents and the editor) in preparing Notes and Drug Monographs relieves adviser/writer paediatricians and pharmacists of the time consuming task of generating text information. Expert advisers now only need to comment on respective sections and make suggestions for inclusions/changes in future editions according to peer experience, practice, and new literature. Dedicated sub-editing teams allow advisers to consider clinical validity and accuracy rather than minutiae. The first edition this year incorporates the best of MfC and the BNF, in-house literature culls, and adviser recommended new information. It has afforded the generation of an evidence database more comprehensive and secure than was the case for MfC. It is hoped that BNF-C will meet all professional needs, but serving the interest of quite different users is a difficult task. Time constraints have meant that the first edition BNF-C reproduces the layout of the BNF, and the optimum presentation for the longer term future has not yet been determined. This, and the fact that success cannot be measured by sales figures, is why feedback of user views will be so important. There will be an insert for this purpose to return views on paper or electronically using the same form via the website. If opinion demonstrates that a different format, style, and content approach is indicated for future editions, changes will be considered and accommodated where possible. 
It is planned to produce a new update edition each year-half as frequent as the BNF.

The BNF in its present format is 50 editions old this year. Here's to the first BNF-C.

Arch Dis Child 2005:90:997-998. doi: $10.1136 /$ adc. 2005.080366
Authors' affiliations

A Elias-Jones, Leicester Royal Infirmary, UK

G Rylance, Royal Victoria Infirmary, UK

Correspondence to: $\operatorname{Dr}$ A Elias-Jones, Department of Paediatrics, Leicester Royal Infirmary, Havelock Street, Leicester LE1 5WW, UK; alun.elias-jones@uhl-tr.nhs.uk

Competing interests : none declared

\section{REFERENCES}

1 Conroy S, Mclntyre K. The use of unlicensed and off-label medicines in the neonate. Seminars in Fetal and Neonatal Medicine 2005; 10:115-22.

2 Chappell K, Newman C. Potential ten-fold drug overdose on a neonatal unit. Arch Dis Child 2004;6:20-3.

3 Davies C. Junior doctors is cleared in baby overdose death. 1999. http:// www.portaltelegraph.co.uk/html Content.

\section{IMAGES IN PAEDIATRICS}

\section{Cutaneous larva migrans, creeping eruption, sand worm}

C utaneous larva migrans is the most common tropically acquired dermatosis. It is characterised by erythema tous, serpiginous, pruritic, cutaneous eruption caused by percutaneous penetration and subsequent migration of larvae of various nematode parasites. ${ }^{1}$ It is most commonly found in tropical and subtropical geographic areas; however, because of the ease and the increasing incidence of foreign travel by the world's population, cutaneous larva migrans is no longer confined to these areas.

We report a 2 year old girl who presented with a four month history of itchy rash on her thigh. There was a history of travel to Jamaica before the onset of the rash. She had a serpigenous, erythematous, itchy rash on the back of her right thigh. She was successfully treated with thiabendazole.

The larvae of the $\operatorname{dog}$ hookworms A braziliense, A caninum, and $U$ stenocephala, together with certain other parasites, produce in humans a skin eruption which differs from that caused by "human" hookworms. Most infections are due to $A$ braziliense. Infections occur on sandy bathing beaches, in children's play areas, and by contact with pet sandboxes. Lesions are most common on the lower legs and buttocks, but also occur on the arms, hands, and face. ${ }^{2}$

The larva, after penetrating the epidermis, is unable to enter the blood or lymph streams and instead burrows just below the corium, travelling up to an inch a day. Papules mark the site of entry and advancing end of the larva, and the tunnelling causes linear, slightly elevated erythematous and serpigenous areas which itch intensely. Vesicles may form along the course of the tunnels and scaling develops as the lesions age. They may develop secondary bacterial infection. The most common sites in children are the buttocks and the dorsa of the feet, but any area can be affected. The eruption generally disappears after $1-2$ months, but may present for 6 months or longer.

\section{Treatment}

The time honoured treatment for cutaneous larva migrans is by freezing of the area with ethyl chloride or similar

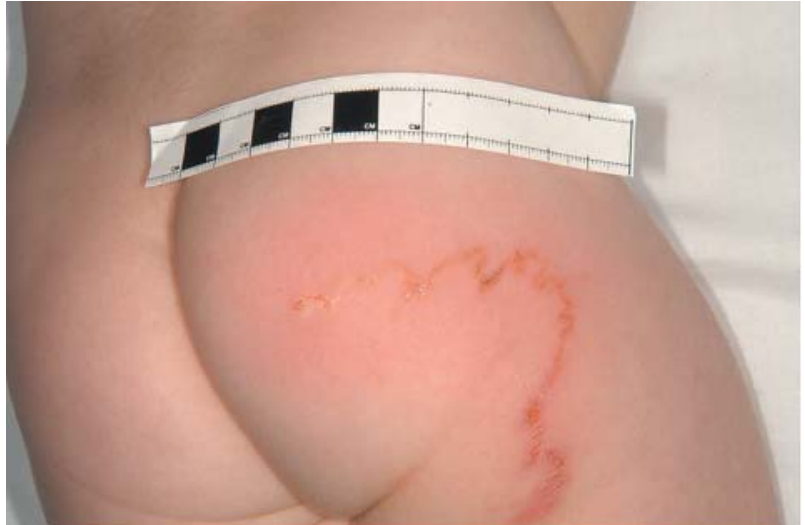

Consent was obtained for publication of this figure

refrigerant sprays. Diethylcarbamazine or thiabendazole can be used. Thiabendazole can also be used topically. ${ }^{3}$

R M Shinkar, R Stocks, E Thomas James Paget Hospital, Great Yarmouth, UK

Correspondence to: Dr R M Shinkar, Department of Paediatrics, James Paget Hospital, Lowestoft Road, Gorleston, Great Yarmouth NR31 6LA, UK rmshinkar1921@yahoo.com Competing interests: none declared Consent was obtained for publication of the figure

\section{References}

1 Knight R. The hookworms. In: Warrell DA, Cox TM, Firth JD, eds. Oxford textbook of medicine, Oxford University Press, 2003:799-800.

2 Goldsmid J, Kibel MA, Mills AE. Cutaneous larva migrans. In: Campbell AGM, Mclntosh N, eds. Textbook of paediatrics, Churchill Livingstone, 1998:1490-1.

3 Van den Enden E, Stevens A, et al. Treatment of cutaneous larva migrans. N Engl J Med 1998;339:1246-7. 